\title{
A improvisação e o jogo com máscara na formação do ator
}

\author{
Guy Freixe \\ Universidade de Franche-Comté - UFC, Besançon, França \\ Email: guy.freixe@gmail.com
}

Este artigo trata sobre a pedagogia do ator, onde as técnicas da máscara e da improvisação são as bases e instrumentos privilegiados para estabelecer o jogo. Esta formação tem como influência a filiação Jacques Copeau Jacques Lecoq - Ariane Mnouchkine, cujos trabalhos privilegiam o jogo onde o homem age e pensa com o seu corpo, podendo inventar, com a máscara, um teatro poético.

\section{Palavras-chave}

Máscara. Improvisação. Jogo.
Cet article traite sur la pédagogie de l'acteur dont les techniques du masque et de l'improvisation sont les fondements et les instruments privilégiés pour établir le jeu. Cette formation a comme influence la filiation Jacques Copeau Jacques Lecoq - Ariane Mnouchkine, dont les travaux privilégient le jeu, où l'homme agit et pense avec tout son corps, pouvant inventer avec le masque un théâtre poétique.

Mots-clés

Masque. Improvisation. Jeu. 
"Você tem uma responsabilidade dupla: receber e ter a generosidade de tentar passar para quem está atrás de você."1

Gostaria de abordar esta questão da transmissão de forma mais pessoal do que eu consegui fazer até agora. Eu, portanto, me referirei aos momentos particulares do meu trabalho como formador em torno do jogo mascarado, enquanto o situo na filiação em que ele se inscreve $^{2}$. Dei o meu primeiro estágio para atores profissionais em junho de 1987, em Montreal, por três semanas. Eu tinha acabado de "deixar" o Théâtre du Soleil (não escrevi "sair" porque eu sabia naquele momento que ia manter de outra forma o companheirismo com a companhia; além de ter chegado nesse estágio com as máscaras do Soleil emprestadas por Erhard Stiefel, o escultor de máscara associado a esse grupo). Eu havia entrado no Théâtre du Soleil alguns anos antes, em junho de 1981, logo após meu treinamento na Escola Jacques Lecoq. Para dar esse estágio, eu poderia, portanto, me apoiar nessas duas experiências. Foi o que fiz. Na preparação das minhas aulas, mais do que as continuidades, foram as diferenças então que apareceram, entre o que para Lecoq era apenas um trabalho de treinamento, onde só passávamos alguns minutos em cena, e a busca de um jogo visando a encarnação de um personagem como eu acabava de experimentar no ciclo de Shakespeare e Sihanouk ${ }^{3}$.

1 Ariane Mnouchkine, introdução, escolha e apresentação de textos de Béatrice Picon-Vallin, Actes Sud-Papiers, coll. "Estágio", Arles, 2009, p. 99.

2 Cf. meu trabalho La Filiation Copeau-Lecoq-Mnouchkine, uma linha da peça do ator, prefácio de Georges Banu, L'Entretemps, coll. "Os caminhos do ator", Paris, 2014.

3 Les Shakespeare (Richard II, La Nuit des Rois, Henry IV 1ère partie), tradução e direção de Ariane Mnouchkine, criação do Théâtre du Soleil, 1981-1984; A História Terrível, mas inacabada, de Norodom Sihanouk, Rei do Camboja, de Hélè-
A escola de um lado, a criação do outro. Procurava uma complementaridade entre a análise de Lecoq dos exercícios de movimento e improvisação e a intensidade dos estados dramáticos exigidos por Mnouchkine. Hoje, o que descobri com esses dois mestres, ligados pelo espírito de uma mesma filiação que remonta à aventura do teatro do Vieux-Colombier de Jacques Copeau (1879-1949), da qual vou tentar esboçar os princípios fundamentais para a atuação do ator, nutre sempre meu ensino ${ }^{4}$.

\section{A Escola de Improvisação}

Duas escolas francesas marcaram particularmente a pedagogia do jogo do ator no século XX: a Escola du Vieux-Colombier de Jacques Copeau (1921-1924) e a Escola Internacional de Teatro de Jacques Lecoq, as quais retomam, estruturando e as aprofundando, as intuições primordiais do "mestre-sonhador"5. Esta pedagogia do jogo do ator, ao negar à análise psicológica e à interpretação dos textos, baseia-se sobretudo na ideia principal de que o homem recebe o mundo pelo seu corpo e pensa e age com seu corpo. $\mathrm{Na}$ abordagem introspectiva, ela se opõe a uma visão fenomenológica. $\mathrm{O}$ ator não parte dele, mas do mundo. Ele visa a impessoalidade para melhor receber a dinâmica dos vivos e reproduzir as múltiplas formas e as estruturas profundas. A máscara é o instrumento privilegiado desta pedagogia

ne Cixous, Theatre du Soleil, 1985.

4 Atualmente ensino palco e improvisação em três escolas nacionais de arte dramática: L'ENSATT em Lyon, a Escola Comédie em Saint-Étienne e a ESNAM em Charleville-Mézières. Também concedo cursos de treinamento profissional de longo prazo aprovados pela AFDAS e pela Região Ile-de-France.

5 A expressão é de Ariane Mnouchkine, em "Contar a história do nosso tempo", L'Âge d'or, première ébauche, Stock, coll. « Théâtre ouvert », Paris, 1975, p. 17. 
da distância que passa pelo apagamento da subjetividade. A coralidade está em processo.

Copeau foi um semeador de sementes. Um iniciador e um despertador. Ele sempre pensou - antes de fundar, há apenas cem anos, o Théâtre du Vieux-Colombier - que a renovação urgente do teatro tinha que passar primeiro pelo ator. $\mathrm{E}$ que era necessário livrar a cena e o jogo de trapaças e falsidades acumuladas por décadas. É do lado da infância, do instinto de jogo da criança, que Copeau foi procurar os fundamentos de sua pedagogia. Teria em mente o aforismo de Baudelaire: "A genialidade é encontrada na infância"? O fato é que Copeau atribuiu a maior importância ao jogo das crianças e julgou não ser aconselhável enviar os seus filhos para a escola, como sua filha Marie-Hélène Dasté nos informa, parta que tirassem de seus jogos sozinhos toda a instrução necessária: "Estávamos habituados por uma espécie de invenção perpétua, encorajada pelo meu pai, e para ele era como a lei, o segredo da educação de um ator: fazer com que ele mantenha seu espírito de infância, para fazê-lo sempre encontrar essa faculdade de admiração e espanto que é a das crianças ${ }^{6 "}$.

Copeau queria preservar no ator essa faculdade de poesia e criatividade, esse estado de jogo composto de disponibilidade, invenção, atenção e imaginação, e é com crianças pequenas de 10 a 14 anos que começa, durante a guerra, a realizar seus primeiros exercícios pedagógicos para se preparar para a abertura de sua Escola.

Ao propor um trabalho em torno das fábulas de La Fontaine, ele se mostra desde o início atentoàs crianças que entram nos personagens

6 Conferência com Marie-Hélène Dasté, Catherine Dasté, Christophe Allwright: uma família de atores, reunião organizada em 19 de março de 1993, no âmbito dos Workshops de formação permanente. pelo corpo: não só para"significar" o animal a fim de que ele seja reconhecível, mas para que o mime internamente, procurando, por exemplo, a marcha silenciosa e desatada do gato para que seu caráter apareça ${ }^{7}$...Copeau quer que seja através do corpo e de uma imaginação inteiramente física que a criança comece primeiro no jogo dramático. Ele desconfia das palavras e da análise psicológica dos personagens na fábula, como se a racionalidade do idioma separasse a criança do primeiro mimetismo e da espontaneidade criativa. Copeau está encantado com esses primeiros exercícios sobre a improvisação de animais e ele está ciente de que eles guiarão sua pesquisa futura: "Esta mina de observação, ele escreveu em seu caderno, e a experiência desses exercícios, será de grande ajuda para o artista para uma representação mais ou menos forçada e caricaturizada dos personagens da comédia"8.

Copeau procura desencadear na criança um jogo pessoal livre, inventivo que "transporte" para o imaginário. Ele irá atribuir a este movimento de libertação a maior importância a partir de então. Mas para isso, a criança deve entrar completamente em seu jogo, que ele realmente joga, seja ele $a k u^{9}$, isto é, que ele dei-

7 Jacques Copeau, Registros VI: L'École du Vieux-Colombier, textos elaborados, apresentados e anotados por Claude Sicard, Gallimard NRF, coll. "Práticas do Teatro", Paris, 2000, p. 99.

8 Idem, p. 101.

9 " $A k u$ ", isto é, totalmente envolvido no jogo. Aqui está o que Copeau escreve em seu Diário sobre o jogo de seus próprios filhos: "Durante muito tempo eu tinha ouvido as crianças brincarem em seus jogos. Termo: aku (pronunciado acou). "Seja $a k u$ ", "você não é $a k u$ ". Eu tenho a explicação. Aku é a abreviatura da palavra dinamarquês akurat, que significa: completamente, completamente. Ser aku no jogo é confundir-se com o personagem, o fato, o evento que se quer representar, é fazer corpo com seu jogo, tomá-lo por verdadeiro, experimentar os sentimentos, imitar gestos com continuidade sem permitir a outros, pais ou eles mesmos, a noção de um fingimento temporário. "Jacques Copeau, Journal 1901-1915, t. Eu, segunda-feira, 4 de março de 1912, Seghers, Paris, 1991, p. 557. 
xe a realidade para viver dentro do imaginário. $E$ para isso, ele precisa da maior liberdade naatuação, sem escrever alegações: "Desconfiar especialmente do que nos aproxima da literatura. Fugir para as antípodas. Nenhum relatório ou comunicação. Não se trata de improvisar depois, mas de improvisar agora. Nenhum intermediário. $\mathrm{O}$ improvisador vale o que vale a pena. E tanto vale a improvisação..."10. Copeau percebe que existem duas escolas possíveis que se opõem à natureza do jogo: a escola de improvisação e a escola de interpretação. $\mathrm{Na}$ improvisação, o ator é confrontado sobretudo com o presente e com o momento compartiIhado com o parceiro e o público.Na interpretação, que parte do texto dramático, deve mediar com a espessura semântica da linguagem. Copeau opta pela improvisação. Ele rapidamente se abre para seus dois companheiros, Charles Dullin e Louis Jouvet, que estão à sua frente. Sua correspondência, de dezembro de 1915 a abril de 1916, gira em torno dessa formidável revolução, que é a descoberta do jogo improvisado e as novas perspectivas abertas por ele. Em janeiro de 1916, Copeau avança outraetapa. Ele descobre com entusiasmo as improvisações clownescas dos Fratellini. Ele escreve para sua esposa:

"Fui cinco vezes no Circo para ver os mesmos palhaços"11. Ele admira seus lazzi, seu jogo constantemente renovado com o público e "a graça alerta de seus corpos treinados"12, o que lhes permite encontrar uma transposição

10 Nota de Jacques Copeau sobre a carta de Louis Jouvet de 10 de janeiro de 1916, nos Registres VI: L'Ecole du Vieux-Colombier, op. cit., p. 110.

11 Jacques Copeau, Cahier "La Comédie improvisée", Registres III : Les Registres du Vieux Colombier I, textes recueillis et établis par Marie-Hélène Dasté et Suzanne Maistre Saint-Denis, Gallimard NRF, coll. "Pratique du théâtre", Paris, 1979, p. 319.

12 Ibid. de sentimentos por uma escrita poética do gesto. Ao falar com eles, ele observa que "é o hábito de trabalhar juntos, sendo o segredo da sua verve"13, e ele é impressionado com a correção da definição de um dos princípios de sua arte: "o movimento, o ritmo e a precisão"14. Então ele estabeleceu um vínculo entre a força dessas improvisações e este espaço, sem qualquer cenário no picadeiro, que permite ao ator implantar o máximo de seu poder sugestivo. Ele observa em seu Diário: "Médrano. O circo, pelo arranjo e as proporções de sua arquitetura, realiza, até certo ponto, esta área vazia do teatro, em que minha imaginação brinca à vontade. Pequena proporção dos personagens e sua completa liberdade de movimentação, com o vazio ao seu redor"15. No vazio do palco, neste espaço de todas as possibilidades, Copeau sonhava em dar importância ao vazio interno do ator. Um vácuo que o faz vibrar conectando-o à autenticidade de seu engajamento. Um vazio misteriosamente completo. Desde então,ele recusa-se a preencher o ator com informações sobre o caráter de seu personagem e prefere atrair o poder misterioso deste vazio para que as asas de sua imaginação se desdobrem livremente. O fascínio exercido pela máscara na École du Vieux-Colombier é melhor entendido quando está vinculado a essa preocupação de alcançar a tal matriz vazia, tão querida para Copeau.

A máscara não foi trazida para a Escola apenas para apagar os tiques e hábitos, não era o instrumento de uma técnica;elaantes apareceu como o instrumento privilegiado deste "transporte" sagrado que, para Copeau, funda o jogo do ator.

13 ld., p. 322.

14 Ibid.

15 Jacques COPEAU, Journal - 1916-1948, t. II, 1ier septembre 1916, Seghers, Paris, 1991, p. 22-23. 


\section{Primeiro, o corpo}

Jacques Lecoq (1921-1999) trabalhou da mesma forma que a iniciada por Copeau, e sua escola repousa sobre os mesmos três pilares: a improvisação, a análise do movimento e o trabalho coletivo dos alunos, que ele nomeará "auto-ensino". Lecoq recebeu esta herança durante os dois anos em que fazia parte do grupo de Jean Dasté, Les Comédiens de Grenoble. Posteriormente, ele conseguiu dar força e coerência aos fundamentos desta pesquisa, fazendo com que a máscara, a comedia dell'arte e o coro trágico fossem as bases de seu ensino que ele colocou em prática com Giorgio Strehler, na Escola do Piccolo Teatro de Milão, em 1951, e que continuou abrindo, em 1956, sua Escola Internacional de Teatro. Lecoq encontrou no trabalho de Marcel Jousse $^{16}$ um suporte teórico para esta pedagogia "mimo-dinâmica", como Copeau e Suzanne Bing, iniciaram no cadinho de sua escola. Pois é aqui que tiveram lugar, pela primeira vez, exercícios mimados onde, sob a máscara, os alunos atuaram como"o vento da manhã que acorda", "duas árvores que se movem suavemente", "o pássaro", "o veado" e "a noite que acorda devagar e se torna a Aurora"17. Lecoq fez essas "identificações",com a dinâmica da natureza e com os animais, a base de seu ensino. Sob a máscara "neutra", este outro nome que ele deu à máscara "nobre" de Copeau, ele

16 Marcel Jousse (1886-1961), élève de Marcel Mauss, a donné des cours d'Anthropologie à la Sorbonne, de 1931 à 1957. Cet enseignement a donné lieu à la publication posthume de trois ouvrages: L'Anthropologie du geste; La Manducation de la parole; Le Parlant, la parole et le souffle, aujourd'hui rassemblés dans L'Anthropologie du geste, Gallimard, coll. "Tel", Paris, 2008.

17 Notes de Marie-Hélène Daste in Jacques Copeau, "Cahier d'exercice de Maiène", Registres VI : L'École du Vieux-Colombier, op. cit., p. 350. criou uma "jornada" para ascender o aluno a algo maior que ele mesmo.

Essas identificações marcam, no processo pedagógico de sua escola, um estágio importante, porque correspondem a um merguIho no invisível. Essa retirada do ego, trazida pela colocação da máscara, é fundamental porque facilita o sentimento interior. Ela dá permissão para se aventurar, por mimetismo, para"o espaço de dentro". Ela protege e unifica: sob essa máscara, independentemente das diferentes culturas e cores da pele, todos os alunos se parecem, e permanece apenas a vibração essencial do ser presente no espaço. "A experiência me provou, escreve Lecoq, que acontecia com essa máscara coisas fundamentais que se tornaram o ponto central da minha pedagogia"18. Esta máscara ensina a ampliar gestos e atitudes; o estudante torna-se mais sensível a este estado de equilíbrio ligado à economia de movimento: "Porque ele conhece o equilíbrio, observa Lecoq, o ator expressará melhor os desequilíbrios de personagens ou conflitos"19. Mas a máscara neutra também traz uma mutação, pois o ator é levado a "essencializar" o gesto, isto é, simplificá-lo, densificando-o de dentro. Como resultado, as linhas principais permanecem e os pequenos detalhes desaparecem. Após os elementos da natureza: água, vento, terra, fogo, as identificações continuam com os materiais: madeira, papel, metal, vidro, borracha, óleo, veludo ou seda... e são tantas aberturas para novos circuitos de sensações, ritmos, formas e energia. Lecoq espera que os alunos "entrem no gosto das coisas, exatamente como um gourmet

18 Jacques Lecoq. Le Corps poétique, en collaboration avec Jean-Gabriel Carasso et Jean-Claude Lallias, Actes Sud-Papiers/ANRAT, Arles, 1999 p. 47.

19 Ibid. 
pode reconhecer as sutis diferenças entre os sabores"20. O ritmo da floresta, a luz do sol, a montanha que se sobe, a encosta que se desce para ver o crepúsculo na planície... o aluno deve primeiro encontrar a impressão em seu corpo antes de dar a ela uma expressão. A identificação "mimo-dinâmica" permite assim reaparecer gestos esquecidos. O aluno encontra, então, o que o corpo manteve em memória de todas as suas experiências sensíveis, e é a partir desses estratos enterrados, que nascem os impulsos profundos de sua criatividade. A natureza, para Lecoq, é a nossa primeira língua e, como ele, adorei dizer isso muitas vezes, "o corpo, lembra"21.

Desde então, a máscara neutra tornou-se uma ferramenta essencial na pedagogia do ator e é ministrada em muitas escolas ao redor do mundo. Esta máscara, eu poderia escrever em meu livro sobre Utopias da Máscara, chamado "nobre" (Copeau), "impessoal” (Dullin), "sublime" (Decroux), "puro" (Sartori), "transparente" (Strehler), antes de Lecoq encontrar o qualificador que permaneceu: “'neutra', é a máscara do exercício ${ }^{22}$. Hoje, tornou-se um ponto de referência inescapável. Na minha pedagogia, além de sua capacidade de despertar a consciência do corpo, ampliar o vocabulário gestual do ator, despsicologizar a atuação e encontrar uma escrita de movimento transposta para o espaço, eu uso muito isso para trabaIhar nesta entidade puramente dramática, esse é o coro. Aqui também, temos que passar por um apagamento do ego do ator para viver um corpo coletivo e se sensibilizar para a escuta

20 Jacques Lecoq. O Corpo Poético, op. cit., p. 55.

21 Idem., p. 56.

22 Guy Freixe. Les Utopies du masque sur les scènes européennes du XXe siècle, L'Entretemps, coll. " Les voies de l'acteur », Montpellier, 2010, p. 272. dos outros e para a dinâmica do movimento no espaço.

\section{Descobrir os princípios do jogo mascarado}

A importância da máscara hoje é mais a ser buscada na pedagogia da atuação do ator do que no uso, em conjunto muito limitado, que lhe é concedido nos espetáculos. Neste espaço de aprendizagem, a máscara ocupa um lugar privilegiado que passa por estágios, workshops, laboratórios de pesquisa. Além da máscara neutra, que não é estritamente uma máscara de jogo, são usados vários tipos de máscara, mas principalmente as de duas tradições teatrais que favorecem a comédia: as meias-máscaras da comédia dell'arte, em couro, e as balinesas, de madeira. Os cursos organizados por Ariane Mnouchkine, no Théâtre du Soleil, oferecem um trabalho que combina essas duas tradições mascaradas. Por mais de trinta anos, nestes cursos-encontros, ela trabalha apenas a partir das máscaras. São elas, eles dizem, quem "fazem todo o trabalho": elas servem para revelar os temperamentos, animar a imaginação, criar o teatro e, consequentemente, permitir o nascimento de um ator. Se a máscara é para Mnouchkine a "disciplina básica"23 do ator, é porque ele ensina primeiro a não tentar mostrar a si mesmo, mas sim a aceitar, a se alienar tanto quanto possível para acolher o "estranho" e o "estranho" em si, que só acontece através deste famoso "estado", do qual Mnouchkine fala frequentemente, e que é apenas outro nome da "jornada" cara a Copeau.

23 Cf. Ariane Mnouchkine, "Máscara, uma disciplina básica", em Le masque. Du rite au théâtre, textes réunis et présentés par Odette Aslan et Denis Bablet, CNRS, Paris, 1985, p. 231234 
Como trabalhar com a máscara? Existe uma técnica específica para abordar esse estilo de jogo? Para Mnouchkine, antes de mais nada, é necessário que o ator se prepare para recebê-la. Para cada máscara, há um histórico e uma "alma completa"24. Quando o ator está na frente de uma fileira de máscaras de tradições diferentes, ele tem diante dele a humanidade em sua quinta essência, presente em todos esses rostos coloridos provenientes da diversidade das culturas do mundo e que são tantas facetas de nosso eu fundo. Para poder receber esta humanidade contida nessas máscaras, o ator deve aprender a estar o mais disponível possível, tão "vazio" como o estrado exigido para esse tipo de jogo.

Em seguida, o processo de trabalho é essencial. Para trabalhar, a máscara solicita uma prática coletiva do teatro. Na verdade, da mesma forma que a máscara não pertence ao ator, - trabalho que é executado sob a máscara pertence a todos os participantes. Pode-se realmente entender esse tipo de encenação, apenas passando alternadamente de um lado para o outro do palco e observando atentamente a mesma máscara interpretada por vários atores. O indivíduo desaparece perante a máscara, que é objeto de uma busca coletiva. Esta é uma das razões pelas quais esse tipo de encenação é encontrado principalmente nas aventuras teatrais que privilegiam uma atuação coletiva.

A máscara impõe suas restrições: obriga o ator a desprender-se dos gestos diários e das atitudes realistas. A transposição torna-se necessária porque, sob a máscara, o ator deve "traduzir" pelo corpo o estado emocional de seu personagem. Os sinais que ele usa

$24 \mathrm{De}$ acordo com a terminologia de Ariane Mnouchkine. devem ser muito precisos, porque a máscara age como uma lupa. Mesmo que ele se mova apenas um dedo do pé, ou um dedo da mão, esse movimento de repente assume uma força extraordinária. Ojogomascarado permite conscientizar a articulação necessária do movimento, prestar atenção ao início e ao fim do gesto e pontuar ritmicamente suas atitudes para que a "frase corpórea" seja legível. A máscara abre o caminho metafórico, no qual o ator mostra, por sinais físicos, o que o afeta internamente, como se ele mostrasse os sintomas de seu afeto psíquico. Nesse sentido, ele é o caminho soberano da arte do ator que, como diz Mnouchkine, "é primeiro uma autópsia e depois um sintoma. Ou, sim, um sintoma, e depois uma autópsia"25. Essa necessidade de transpor o estado interno em uma forma corpórea rigorosa desenvolve a imaginação, considerada como o "músculo" principal do ator. As restrições da máscara, portanto, abrem a liberdade de expressão inesperada e a uma escrita controlada de sinais, combinando ímpeto emocional e a forma corporal rigorosa.

Assim que o ator entra na cena, é preciso que todo o seu corpo mostre, com a maior clareza possível, seu personagem, seu estado e seu comportamento. A palavra não deve vir muito cedo para que o ator expresse em e pelo seu corpo o que ele tem antes das palavras, e que constitui o motor essencial da ação dramática. Ariane Mnouchkine gosta de ensinar este be.a.ba do jogo, retornando constantemente aos fundamentos do que ela gosta de chamar de "o" teatro. Tem um gosto por aprender, pelos primórdios e, acima de tudo, por dar à luz o ator. Ela, muitas vezes,

25 "Um grupo, se é digno do nome, é sempre uma escola", Entrevista com Ariane Mnouchkine, em Guy FREIXE, 'La Filiation Copeau-Lecoq-Mnouchkine', uma linha da peça do ator, op. cit., p. 268. 
define seu trabalho como a de uma parteira. Ela dirige a atuação do ator com tanto domínio que seus cursos, esperados por centenas de jovens atrizes e atores, são ótimas aulas de teatro. Com muito humor, fervor, compromisso ilimitado, ela ensina aos jovens atores, através de uma peça máscara, a escrita desse ator, passando pela linguagem do corpo. Através de seus olhos, seu riso, suas indicações, ela o ajuda a definir sua silhueta, sua abordagem, e melhor desenhar suas atitudes, eliminar um gesto tão parasitário e, acima de tudo, intensificar seu motor de jogo, que às vezes chama de "sua pequena música interior" 26 . Desde o primeiro passo em cena, ela já viu tudo: o corpo errado, o ritmo embaçado, a agitação febril. Ela simplesmente diz: "Não. Retome.”É assim que ela encontra um elemento justo no jogo em que ela pode apoiar, ela então pede que o ator comece de novo; e com infinita paciência, dez vezes, vinte vezes consecutivas, ela pode retrabalhar o mesmo detalhe da peça para que o gesto refine e traduza, em infinitas variações, a paixão do personagem. Ela tenta fazê-lo entender o que a escrita significa, quando todo o corpo é perfeitamente desenhado, do dedo do pé até o ponto do cabelo. É pela precisão de uma atitude, o cuidado de um detalhe, o que ela chama de "pequeno", que o ator atinge o "grande". E para isso, ele nunca deve jogar as duas coisas ao mesmo tempo. Ele deve escrever uma letra após a outra. Ariane pede ao ator que seus gestos sejam puros, atenciosos, que a periferia de seu corpo seja cuidadosamente esculpida, com ângulos vivos, e que paradas deem ritmo ao movimento...

Esta escrita dos signos corporais, a que o jogo mascarado inicia, nunca é trabalhada

26 Sempre de acordo com a terminologia de Ariane Mnouchkine. como um fim em si. Deve vir a exteriorizar o que é mais íntimo, a própria verdade dos sentimentos. A grande lei, muito misteriosa, reside nesta passagem entre o interior e o exterior, entre o estado e a modelagem pelo corpo. Ariane Mnouchkine permanece atentapara que esta não se torne uma deformação, e é por isso que rejeita a caricatura como sendo uma facilidade, até mesmo um engano. Toda a arte do ator consiste precisamente no fato de que sua escrita vem para exteriorizar o interior, sem cair na exterioridade. $E$ isso é exatamente o que os grandes professores orientais ensinam. Se Mnouchkine se baseia na máscara para guiar o ator no jogo, é isso, bem usado, atua em ambas as direções: permite definir a forma externa, abrindo internamente novos circuitos sensíveis e criativos. Ela sensibiliza o ator para o "grafia" do corpo, enquanto serve como um trampolim para sua imaginação.

Figura 1: Abrir as possibilidades com as máscaras de diferentes tradições $@$.

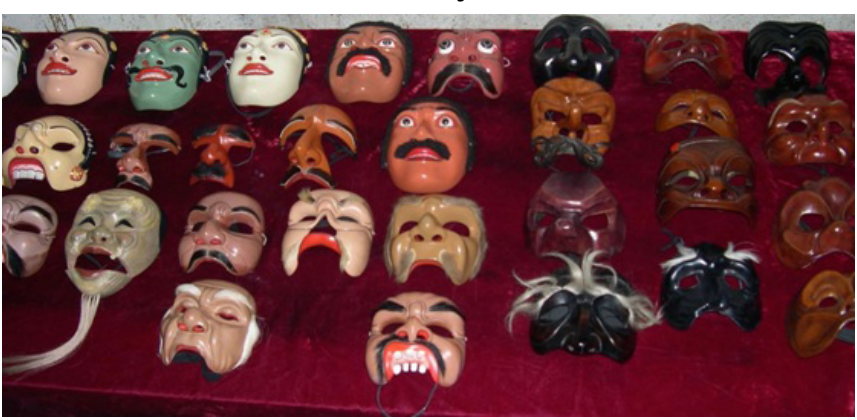

Fonte: o autor.

Estes são os fundamentos da encenação com máscaras, que eu próprio procuro transmitir no meu ensino teatral. Como acabamos de ver, este recurso apela para a imaginação do ator e encontra seu terreno favorito na improvisação. Mas se pode improvisar a partir de suportes muito diferentes: um tema geral (praga, guerra, novas odisseias de migrantes contemporâneos, naufrágio e chegada em uma ilha, etc.), uma simples roteiro (com situação, 
personagens, desenvolvimento de um conflito dramático); ou se apoiando em um texto. Faz anos que eu gosto de recorrer a esse tipo de confronto, que não ocorre sem tensões, entre as restrições da máscara e os requisitos do texto.

A máscara é uma ferramenta magistral na medida em que ela obriga o ator a encontrar uma forma. Mas deve-se admitir, a máscara também é tirânica. Ela exige que seja obedecida. A maquiagem aceita muito bem se o ator não encontra imediatamente o que ele tem para atuar. A máscara, não. Ele deve vivê-la imediatamente, sem esperar, assim que entrar no palco, desde seu aparecimento. A máscara se impõe ao ator e impõe suas leis. Ela é de uma soberania implacável. Ela não se submete a nenhuma outra lógica que a sua. Esta é a razão pela qual a improvisação livre é a forma mais adequada e que o encontro com um texto deve ser uma necessidade. Quando ocorre essa conjunção - entre o ator, a máscara e o personagem tal como aparece nas próprias palavras do autor - pode ser formidável. Mas, se essa conjunção não for perfeita, o texto não será entendido, pois a máscara irá impor seus códigos de jogo. Se um ator, por exemplo, quer trabalhar Puck em Sonho de Uma noite de Verão, com a máscara de Polichinelo, Puck se tornará Polichinelo. Será o mesmo para Figaro, Cyrano, Vladimir ou Estragon: Polichinelle em todos os casos irá se impor. A máscara nivelará as diferenças no estilo de escrita e nas apostas dramáticas. A máscara usa mais um texto como alimento para atuação do que ela se coloca a seu serviço.

Sob a máscara, tudo deve ser mostrado ao espectador, objetivado de alguma forma. As formas extremas, como a farsa ou a tragédia, obtêm deste tratamento porque há em sua es- crita a parte da generalização e da essencialização que a máscara exige. Um tipo de escrita realista e psicológica, por outro lado, será suprimido recorrendo à máscara. Se tomarmos o caso de Tchekhov, por exemplo, a maioria de suas peças de um ato resistem a esta prova de máscara, que irá acentuar sua dimensão farsesca, mas se alguém quiserfazer a experiência com "A Gaivota" com máscaras - uma vez superada a imensa dificuldade de encontrar (ou fazer) máscaras adequadas para este trabalho - perceberia rapidamente a impossibilidade de atuar no que o trabalho do idioma já faz: mascarar a intenção profunda com uma frase aparentemente inócua. A máscara, nesse caso, não revela nada. Em vez disso, obscurece a atuação. O trabalho com o discursofeito pelo poeta já faz o papelda máscara.

A máscara é em si um texto. Ela contém seu próprio texto porque é uma partitura precisa, como pode ser um papel teatral. Por outro lado, o texto atua como uma máscara, porque destaca ou esconde certos pensamentos do personagem. Esses dois instrumentos são muito poderosos para o ator, pois eles permitem que ele vá para as áreas fora de sua experiência habitual. Mas, para poder usá-las juntos, sua complementaridade deve ser necessária, caso contrário, seu poder específico desaparecerá e elas se anularão mutuamente.

Uma vez que a máscara deve estar em perfeita harmonia com o texto, uma das dificuldades está na gama de máscaras que oferecemos aos atores, no contexto de uma exploração cênica. Pois, se oferecemos apenas máscaras de commedia dell'arte, por exemplo, limitamos fortemente as ressonâncias de certos textos. De fato, a tradição da comédia italiana - de Ruzzante a Goldoni, através de Molière, Marivaux e os mestres do teatro de Foire 
- encontra um formidável trampolim nesses encontros com tipos tradicionais como PantaIon, Harlequin e outras máscaras da commedia dell'arte; essas mesmas máscaras não permitem uma leitura aberta, significativa e inventiva de textos mais contemporâneos. Muitas convenções estão contidas nelas e impedem o seu brilho. É uma boa ideia usar máscaras menos carregadas culturalmente para abrir a imaginação e o significado e propor, por exemplo, meias-máscaras balinesas para acentuar o estilo burlesco de algumas das peças de Brecht, o que aumentará o efeito da "estranheza" relevante e lúdico ${ }^{27}$. Daí a importância de se abrir para outras tradições extra ocidentais de teatro mascarado (e especialmente asiáticos, tão ricos neste campo) e trabalhar com um fator de máscaras para que ele possa propor novos tipos adaptados aos personagens e autores estudados.

O interesse desse tipo de confronto entre máscara e texto parece ser duplo. Primeiro, permite que a máscara seja questionada como um objeto e identifica concretamente seus vários usos: desde a máscara até a máscara oriental, da meia-máscara a toda a máscara articulada, da máscara-prótese à máscara oversized. Por outro lado, ao questionar o jogo de forma incomum, ele renova a abordagem interpretativa do texto, chegando a combinar a abordagem intelectual com a abordagem orgânica. A máscara propõe toda uma série de "deslocamentos" que se tornam trampolins insuspeitos para o ator, bem como para a escrita cênica: mudança de visual e som, autonomia de gestos, importância de paradas e rupturas, musicalidade reforçada de deslocamentos e

27 Brecht pergunta em uma nota de quanto custa o ferro: "Esta pequena peça deve ser tocada no estilo burlesco do knockabout", em Bertolt BRECHT, Teatro Completo, L'Arche, 1979, p. 134. frases. A poética da máscara abrange todos esses deslocamentos, esse dever para o ator de ir às áreas transfronteiriças, para frustrar os limites e inventar um teatro poético privilegiando o imaginário.

Tradução de Clóvis D. Massa

Recebido: 03/01/2017

Aprovado: 12/11/2017 